\title{
Characterization of neutrophil adhesion to different titanium surfaces
}

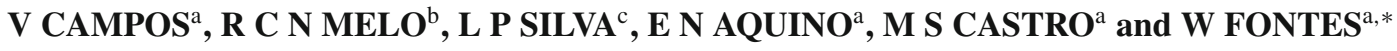 \\ ${ }^{a}$ Cell Biology Department, University of Brasília, Brasília - DF, Brazil \\ ${ }^{b}$ Department of Biology, Federal University of Juiz de Fora, Juiz de Fora - MG, Brazil \\ ${ }^{\mathrm{c}}$ Embrapa Recursos Genéticos e Biotecnologia, Brasília - DF, Brazil
}

MS received 10 August 2012

\begin{abstract}
Although titanium (Ti) is known to elicit a foreign body response when implanted into humans, Ti implant healing resembles normal wound healing in terms of inflammatory cell recruitment and inflammation persistence. Rough implant surfaces may present better conditions for protein adsorption and for the adhesion of platelets and inflammatory cells such as neutrophils. Implanted biomedical devices initially interact with coagulating blood; however, direct contact between the oxide layer of the implant and neutrophils has not been completely described. The aim of the present study is to compare the behaviours of neutrophils in direct contact with different Ti surfaces. Isolated human neutrophils were placed into contact with Ti discs, which had been rendered as 'smooth' or 'rough', following different surface treatments. Scanning electron microscopy and flow cytometry were used to measure cell adhesion to the surfaces and exposure of membrane proteins such as CD62L and CD11b. Topographic roughness was demonstrated as higher for SLA treated surfaces, measured by atomic force microscopy and elemental analysis was performed by energy dispersive X-ray, showing a similar composition for both surfaces. The adhesion of neutrophils to the 'rough' Ti surface was initially stronger than adhesion to the 'smooth' surface. The cell morphology and adhesion marker results revealed clear signs of neutrophil activation by either surface, with different neutrophil morphological characteristics being observed between the two surface types. Understanding the cellular mechanisms regulating cell-implant interactions should help researchers to improve the surface topography of biomedical implant devices.
\end{abstract}

Keywords. Titanium surfaces; neutrophil morphology; adhesion molecules; inflammatory response; flow cytometry; scanning electron microscopy.

\section{Introduction}

In 1940, Bothe and Davenport (1940) first reported that the pure metal titanium (Ti) was well tolerated when implanted into bone tissue and that the bone tended to grow into contact with the metal. Since that time, Ti implant systems have been exploited as bone tissue replacements (Leventhal 1951; Albrektsson 1983). Rough-surfaced implants develop bony contacts earlier than smooth-surfaced implants (Albrektsson et al 1981) and have been identified as potentially superior in terms of implant integration (Thomas and Cook 1985; Salzman et al 1987). Although implanted Ti elicits a foreign body response, implant healing resembles normal wound healing in terms of inflammatory cell recruitment and inflammation persistence (Rosengren et al 1944; Thomsen et al 1997).

Surgical implant insertion typically results in local tissue damage and bleeding. Consequently, almost any medical device introduced into the human body initially will interact with coagulating blood, instantly acquiring an adsorbed layer

\footnotetext{
*Author for correspondence (wagnerf@unb.br)
}

of host plasma proteins (Sevastianov 1988; Vroman 1988). Albumin can be used to passivate the implant surface (Barbotin and Brown 1976; Sevastianov 1988), while complement activation products such as C3a, C5a and sC5b-9 increase neutrophil recruitment (Craddock et al 1977; Nusbacher et al 1978). Fibrinogen also plays a role in the acute inflammatory response (Tang and Eaton 1993). Complement activation is initiated by the classical or alternative pathways, depending on the surface of the material, and is maintained by the latter (Mcnally and Anderson 1994). Thus, it is well established that different biomaterial surfaces have different complement-activating properties (Ekdahl et al 1993). Implant substratum topography has been identified as a key factor that influences the attachment and differentiation of many cell types (Chehroudi et al 1992; Kim et al 2006).

Within $10 \mathrm{~s}$ of implant exposure to blood, platelets arrive at the implant surface; within $10 \mathrm{~min}$, the platelets express P-selectin (CD62P) (Nygren et al 1997). The titanium surface is not inert and induces the production of factors that are chemotactic to PMN granulocytes via complement activation. Granulocytes arrive at the blood-titanium surface within $10 \mathrm{~min}$, where they adhere in a quantity 
that indicates their active recruitment to the surface (Hong et al 1999). Previous investigations of blood-biomaterial interactions primarily have used whole blood, evaluating the process of cross-talk among different blood components (Fontes et al 1988; Hong et al 1999). Adhesion of polymorphonuclear neutrophils (PMNs) to surfaces in contact with whole blood presumably depends on the previous interaction of the surfaces with proteins and platelets. However, little is known about the behaviour of neutrophils, when they come into direct contact with different Ti surfaces in the absence of inflammatory mediators from plasma or other cells.

Neutrophils are effector inflammatory cells that are activated by various mediators. The first sign of physiological neutrophil activation is chemotaxis, which begins with neutrophil rolling on the endothelium (Morris et al 2008). The rolling velocity decreases following the adhesion of Lselectin (CD62L) to its endothelial ligand, P-selectin glycoprotein ligand (PSGL)-1 (Maciel et al 2003; Castro et al 2006a). L-selectin on the neutrophil surface is ready for adhesion, but the process depends on PSGL-1 activation (Tedder et al 1995). L-selectin is a type-1 transmembrane protein that is expressed constitutively and uniformly by neutrophils. The adhesive role of L-selectins includes facilitating direct and indirect neutrophil tethering along the vascular wall (Rainer 2002). Consistent with its broad role in directing leukocyte accumulation, L-selectin expression on the neutrophil surface is tightly regulated (Sperandio et al 2003; St Hill et al 2003). The regulatory mechanisms include rapid and efficient L-selectin downregulation from the neutrophil surface upon cellular activation by various stimuli, as well as the release of nearly all L-selectin molecules from the neutrophil surface by a proteolytic process (Kishimoto et al 1989). L-selectin binding to the endothelium can be broken by the rolling movement or by L-selectin cleavage via a neutrophil-released metalloprotease (Ivetic and Ridley 2004).

Following rolling, neutrophil degranulation exposes the $\alpha \mathrm{m}$ integrin subunit (CD11b) on the cell surface and triggers firm adhesion. Firm adhesion primarily occurs through the binding of $\mathrm{CD} 11 \mathrm{~b}$ to $\mathrm{CD} 18$ subunits and formation of the Mac-1 ( $\alpha \mathrm{m} \beta 2$;CD11b/CD18) integrin complex. Integrins are important adhesion receptors that transmit conformational changes across the membrane in a bidirectional manner. Integrin $\alpha$ and $\beta$ subunits form a head and two long legs in the ectodomain and span the membrane (Maciel et al 2003; Xiao et al 2004). Mac-1 binds to intercellular adhesion molecule (ICAM)-1 on endothelial cells or other neutrophils (Todd 1996; Wagner and Roth 2000). Neutrophil activation is associated with a decrease in L-selectin and an increase in the Mac-1 complex on the membrane. Utilizing whole blood into contact with Ti sheets, Eriksson and Nygren (2001) reported a high initial expression of L-selectin (at 8 and $16 \mathrm{~min}$ ) that decreased when CD11b overexpression was observed (after 32-64 min).

Following firm adhesion, cell spreading and transendothelial migration (TEM) occur. These processes include the formation of membrane protrusions (lamellipodia and lamellae) at the leading edges of cells, and membrane adhesive interactions with substrates. Cell spreading and migration require cell polarization and coordinated cytoskeletal dynamics (Lauffenburger and Horwitz 1996; Ridley et al 2003).

Because neutrophils quickly encounter Ti surface during implant placement, the aim of this work was to characterize the behaviour of neutrophils at different contact times with Ti implant. We also aimed to elucidate whether the surface topography influenced the adhesion characteristics, cell morphology, or expression of CD62L and CD11b.

\section{Materials and methods}

\subsection{Neutrophil separation}

Fresh peripheral blood was obtained by venipuncture into heparin-containing tubes from healthy donors who were not taking any medication. Informed consent was obtained from all volunteers before obtaining blood. Neutrophils were separated on a density gradient as described by Castro et al (2006b). Briefly, blood was centrifuged through 60 and 70\% density layers of Percoll (Amersham Biosciences, Uppsala, Sweden). Residual erythrocytes were removed by osmotic lysis. An aliquot was taken for cell counting and viability analysis by microscopy. Except for the density gradient step, the neutrophil isolation process was performed at room temperature to avoid cellular activation. Isolated neutrophils were resuspended in HBSS containing physiologic concentrations of $\mathrm{Ca}$ and $\mathrm{Mg}$.

Neutrophils were placed in $15-\mu \mathrm{L}$ drops on to the Ti surface. The cell suspension volume was sufficient to cover the entire metal surface. Ti pieces were placed in a humid chamber at room temperature. After contact with the Ti surface for $5,15,30,60$ or $120 \mathrm{~min}$, the cells were removed by centrifugation and submitted to electron microscopy and flow cytometry analyses.

\subsection{Surface preparation}

Commercially pure titanium (CpTi) ASTM grade 4 discs (Neodent Sistema de Implantes, Brazil), $1 \mathrm{~mm}$ in thickness and $6 \mathrm{~mm}$ in diameter, were used. The discs previously were sterilized and packaged by the manufacturer. Two types of discs were employed: machined-polished 'smooth' discs and sandblasted, large-grit, acid-etched (SLA) 'rough' discs, which were obtained by acid etching with $\mathrm{HCl} / \mathrm{H}_{2} \mathrm{SO}_{4}$ after sandblasting.

\subsection{Surface analysis}

2.3a Wettability: The surface wettability was estimated by placing a $15-\mu \mathrm{L}$ drop of water on each surface. The spreading of water was calculated based on the average of five measurements of the angle formed between the tangent to the drop and the surface lines. 
2.3b Scanning electron microscopy (SEM): Ti surfaces were submitted to field emission SEM (JEOL JSM 6340F, Hitachi Co., Tokyo, Japan) without gold sputtering for surface morphology analysis. The microscope was operated at an accelerating voltage of $15 \mathrm{kV}$, perpendicular to the surfaces, and original magnification of 160 and $1400 \times$ (Erlandsen et al 2001).

2.3c Energy dispersive $X$-ray $(E D X)$ : Elemental analysis and mapping were performed by EDX analysis (XL30 FEG series, Oxford Instruments, Philips). The surface elemental composition of the plates was also evaluated. The relative atomic concentrations were calculated from the relative peak heights after correction by tabulated sensitivity factors (Kumazawa et al 2002).

2.3d Atomic force microscopy (AFM): Surfaces were evaluated by AFM (SPM-9600, Shimadzu, Japan) in ambient air contact mode with a scanner with lateral dimensions of $125 \times 125 \mu \mathrm{m}$. Pyramidal silicon nitrite $\left(\mathrm{Si}_{3} \mathrm{~N}_{4}\right)$ tips integrated with cantilevers with a spring constant of $0.15 \mathrm{~N} / \mathrm{m}$ were utilized. The adopted resolution was $512 \times$ 512 lines into a scanning area of $50 \times 50 \mu \mathrm{m}$. Repeated scanning procedures (including trace-retrace and angle variations) were performed at the same region to confirm that no morphological alterations occurred during the analysis procedure (Valois et al 2008). Nanoroughness parameters were measured in four different regions of each sample for statistical comparisons.

\subsection{Cell analysis}

2.4a SEM: After exposure to $\mathrm{Ti}$ surfaces, neutrophils were fixed in $2 \%$ glutaraldehyde in 0.1 cacodylate buffer ( $\mathrm{pH} 7.4$ ), postfixed in $1 \%$ osmium tetroxide, dehydrated in increasing ethanol concentrations, critical point dried, mounted on aluminum stubs and gold-sputtered. Cell morphological changes were observed using SEM with an accelerating voltage of $10 \mathrm{kV}$ and original magnification of 600-12000×.

2.4b Cell detachment: Cells were removed from the disc surface utilizing a method developed in our lab to compare the adhesive forces of cells on different surfaces. Briefly, discs containing neutrophils were inverted and placed in a tube assembly that exposed the Ti-adherent cells to a controlled $g$-force orthogonal to the surface. The tube assembly included an Eppendorf tube (with a cut bottom) that was placed in a $15-\mathrm{mL}$ Falcon tube. The cells were placed facing the bottom of the tubes. The empty space between the disc surface and the bottom of the Falcon tube was filled with $130 \mu \mathrm{L}$ of HBSS. The whole assembly was centrifuged (Himac CR 20B2, Hitachi, Japan) at $290 \mathrm{~g}$ for $20 \mathrm{~min}$. The acceleration/deceleration of the centrifuge was set to level 2 . The detached cells were collected, counted and analysed by flow cytometry for size, granularity and surface expression of CD62L and CD11b.

\subsection{Exposure of adhesion receptors on neutrophil surface}

After exposure of the neutrophils to smooth and rough plates of Ti for different time periods, the neutrophil surface was analysed for CD62L and CD11b expression. Neutrophils were exposed to Ti plates for 5, 15, 30, 60 or $120 \mathrm{~min}$. The cells were removed from the discs by centrifugation $(290 \mathrm{~g}$ for $20 \mathrm{~min}$ ). Cells were incubated with both FITC-conjugated anti-CD62L and R-PE-conjugated anti-CD11b for $5 \mathrm{~min}$ at $25^{\circ} \mathrm{C}$. Fluorescence was detected by flow cytometry (FACSCalibur, BD Becton Dickinson, Mountain View, CA, USA), typically collecting 10000 events/sample. The flow cytometer was calibrated before use with commercially available fluorescent beads.

CellQuest $^{\mathrm{TM}}$ software was used to control data acquisition and to analyse the data. Isolated neutrophils were defined by their morphometric characteristics in the forward-scatter $v s$ side-scatter density plots. Neutrophils incubated with PMA $\left(100 \mathrm{ng} / \mathrm{mL}\right.$ ) for $2 \mathrm{~h}$ at $25^{\circ} \mathrm{C}$ and centrifuged in the absence of Ti were used as a positive control. Cells incubated in HBSS, submitted to the same processing were used as a negative control.

\subsection{Statistical analysis}

Each experiment was repeated atleast 3 times. Student's $t$ test was used to compare the quantity of cells removed from smooth and rough surfaces. Analysis of variance (ANOVA) was used to compare the cell percentage and mean fluorescence intensity (MFI) of CD62L and CD11b among controls and smooth and rough surfaces. For ANOVA and $t$-tests, statistical significance was defined as $p<0$. 05. The Mann-Whitney U test was used to determine differences in the surface attachment area of surface-adherent cells, with $p<0.01$ being defined as statistically significant.

\section{Results and discussion}

\subsection{Wettability}

It is well known that the spreading of water or hydrophobicity is increased on rough surfaces. Accordingly, smooth and rough disc surfaces displayed contact angles of $45 \pm 2^{\circ}$ and $30 \pm 2^{\circ}$, respectively consistent with previous results (Ponce-Fatou 2006).

\subsection{Surface analysis by SEM and AFM}

SEM results revealed different microtopographies for different disc surfaces. The smooth surfaces exhibited fine grooves (figure 1(a and c)), while the rough (SLA) surfaces exhibited a textured topography with particularly deep and narrow indentations (figure $1(\mathrm{~b}$ and $d)$ ). Similar results were also obtained using AFM (figure 2). 

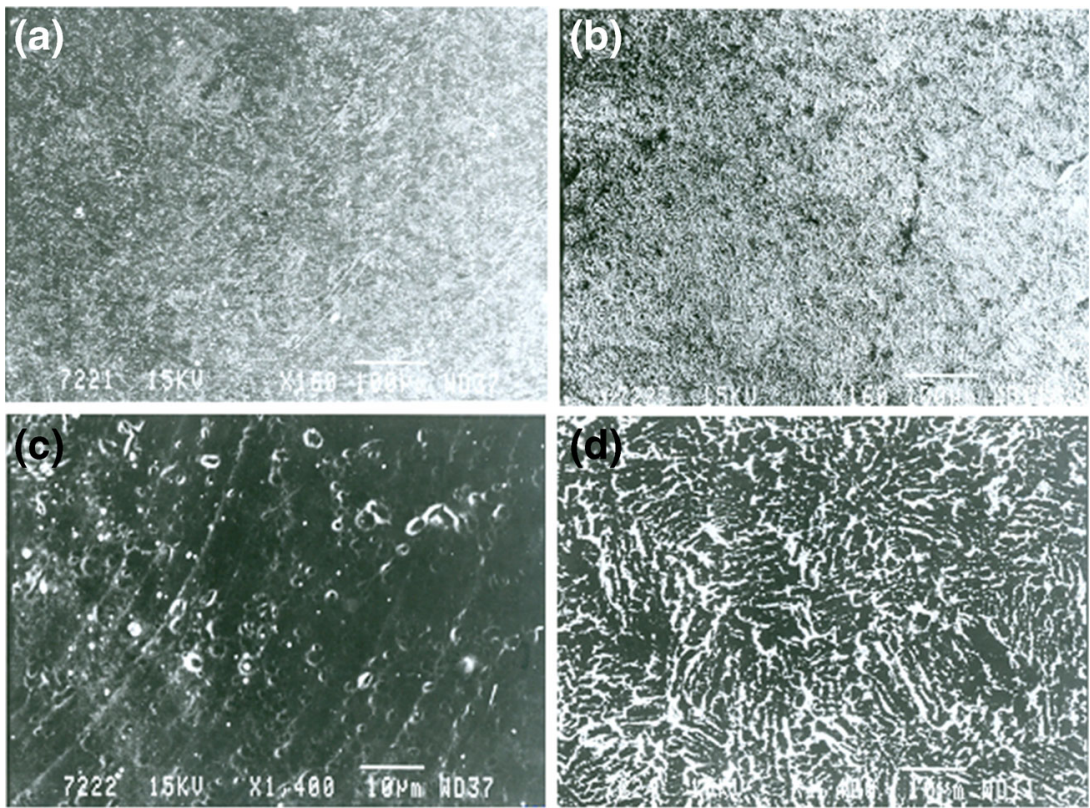

Figure 1. SEM images of Ti surfaces obtained at $1.5 \mathrm{kV}$ : (a) Smooth surface, $160 \times$

(b) rough surface, $160 \times($ c) smooth surface, $1400 \times$ and (d) rough surface, $1400 \times$.

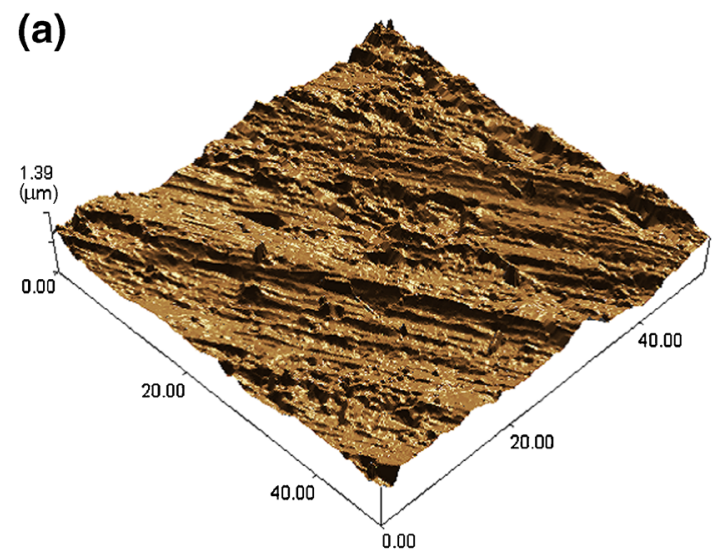

$50.00 \times 50.00(\mu \mathrm{m}) \quad Z=0.00-1390.71(\mathrm{~nm})$ Lisa-1

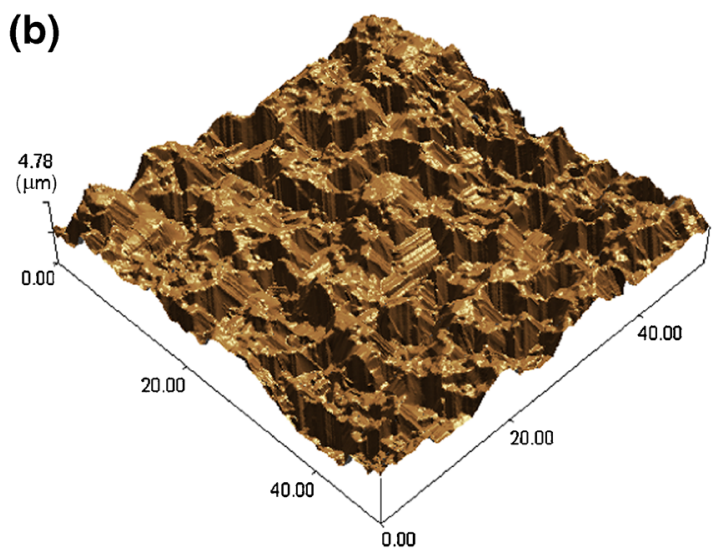

$50.00 \times 50.00(\mu \mathrm{m}) \quad Z=0.00-4776.32(\mathrm{~nm})$

SLA-4

Figure 2. Representative AFM images of smooth (a) and rough (b) Ti surfaces.

The arithmetic average roughness $\left(R_{\mathrm{a}}\right)$, maximum height $\left(R_{\mathrm{z}}\right)$, average roughness from 10 points of the sample $\left(R_{\mathrm{zjis}}\right)$ and root mean square roughness $\left(R_{\mathrm{q}}\right)$ values for the smooth surface were significantly $(p<0 \cdot 05)$ lower than those for the rough surface. The mean high $\left(R_{\mathrm{p}}\right)$ and deep mean $\left(R_{\mathrm{v}}\right)$ also differed significantly $(p<0 \cdot 05)$ between the surface types (figure 3).

\subsection{Elemental composition by EDX}

EDX analysis revealed Ti as the only major component and the presence of carbon on smooth Ti surfaces. The rough surfaces exhibited the same composition, except that minute

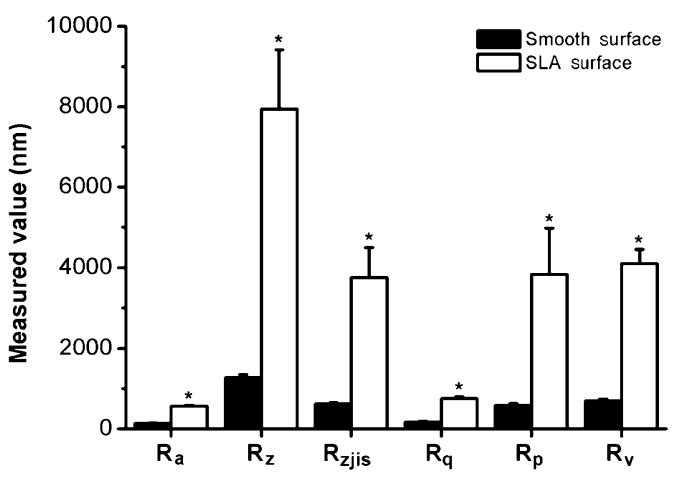

Figure 3. Surface analyses from AFM images were used to determine $R_{\mathrm{a}}, R_{\mathrm{z}}, R_{\mathrm{zjis}}, R_{\mathrm{q}}, R_{\mathrm{p}}$, and $R_{\mathrm{v}}$ values for rough and smooth surface types $(* P<0 \cdot 05)$. 
amounts of contaminants (e.g. C, Si, $\mathrm{Cl}$ and $\mathrm{Na}$ ) were also detected (data not shown).

\subsection{Cell detachment}

More cells were released from the smooth disc surface than from the rough surface after 5 or $30 \mathrm{~min}$ of incubation ( $p<0.05$ by Student's $t$-test). For each surface type, the number of cells removed decreased between 5 and $30 \mathrm{~min}$ of incubation ( $p<0 \cdot 05)$ followed by a constant level of adhesion after $30 \mathrm{~min}$ (figure 4 ).

\subsection{Cell morphology analysis by SEM}

Adherent cells were observed on both the surfaces at all the times analysed. At $15 \mathrm{~min}$, most cells exhibited a round morphology with slight spreading. However, cells adhering to the rough surface had a higher proportion of short villi and folds than cells on the smooth surfaces (compare figure 5(c) and (d)). Cells on the rough surfaces (figure 5(d), arrowheads) were characterized by the presence of tiny surface openings ( $~ 80-200 \mathrm{~nm}$ in diameter) that increased in number after $1 \mathrm{~h}$ of contact (figure 5(f), arrowheads). These openings, which were observed in lower proportion in cells exposed to smooth surfaces (figure 5(c), arrowheads), may be related to the release of secretory products through vesicular transport upon cell activation.

After $2 \mathrm{~h}$ of contact, different morphological features were displayed by PMNs adhering to the smooth or rough surfaces (figure 6). Whereas most cells on smooth surfaces showed a rounded morphology, cells adhering to the rough surfaces were spread out and appeared as flat cells with a large area of attachment to the Ti surface (compare figure 6(a) and (b)).

To quantify the attachment area of PMNs on either surface after $2 \mathrm{~h}$ of contact, a total of 112 cells were delineated (as in figure 6(ai) and (bi)) and the cell area was measured using the software ImageJ 1.41 (National Institutes of Health, USA).
PMNs adhering to the rough surface had a 4-fold higher surface attachment area than cells adhering to the smooth surface (mean \pm SEM of $132.57 \pm 5.66 \mu^{2}$ and $32.36 \pm$ $0 \cdot 78 \mu \mathrm{m}^{2}$, respectively; $p<0 \cdot 01$ ) (figure 6(c)). Cells adhering to the rough surfaces showed prominent shape changes (figure $6(\mathrm{~b}, \mathrm{bi})$ ) and more cytoplasmic surface projections (figure 7(b), arrowheads) than cells on the smooth surfaces (figure 7(a)), which showed large surface projections only occasionally.

\subsection{Exposure of adhesion receptors on neutrophil surface}

Since the neutrophils showed different morphologies and adhesion forces when in direct contact with smooth or rough $\mathrm{Ti}$ surfaces, we monitored the exposure of CD62L and $\mathrm{CD} 11 \mathrm{~b}$ on the cell surface. The weak adhesion marker CD62L is normally present in quiescent neutrophils and is removed after adhesion or PMA activation (Ivetic and Ridley 2004). The firm-adhesion marker CD11b is integrated into the Mac-1 complex and normally is exposed at the cell surface after cell activation with PMA (Vedder and Harlan 1988). The data were obtained by flow cytometry and subjected to ANOVA test.

There was no significant difference in the exposure of CD62L and CD11b between cells adhering to the smooth or rough plates. Contact with either surface elicited more CD62L presenting cells than the positive control and fewer CD62L presenting cells than the negative control (figure 8). Fewer CD11b presenting cells were observed among the Ti-exposed cells than among the positive or negative controls (figure 9). The quantities of CD62L (figure 8) and CD11b (figure 9) molecules (MFI, boxes) on the surfaces of Ti-exposed cells were not significantly different compared with the negative control. However, more CD62L and fewer CD11b molecules were observed on Ti-exposed cells compared to the positive control.

Over the last decade, understanding the mechanisms of leukocyte migration into areas of inflammation has increased

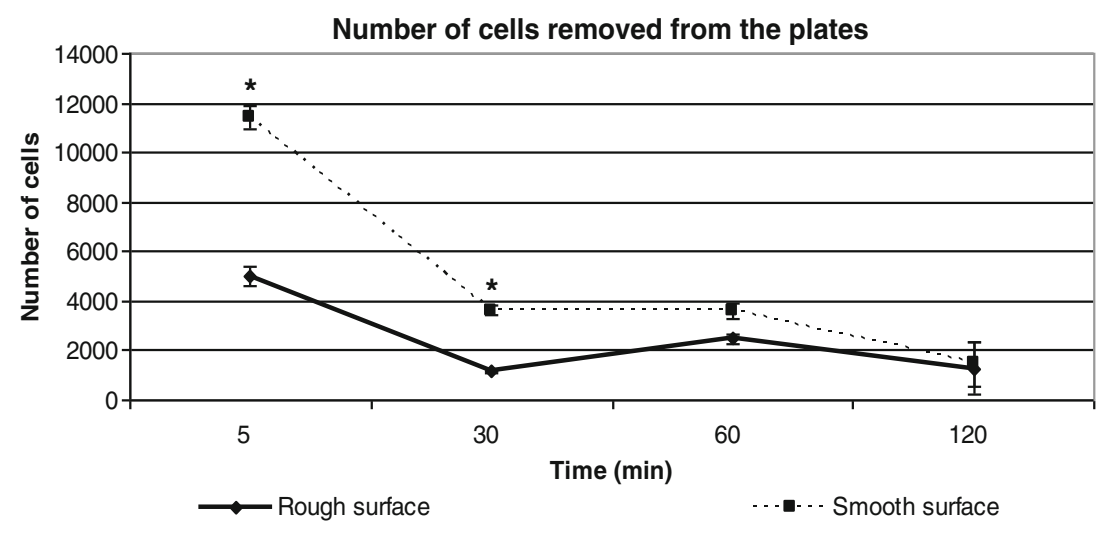

Figure 4. Number of cells removed from plates. Cells were incubated for 5-120 min on smooth or rough surfaces and were removed by centrifugation $(* P<0 \cdot 05)$. 

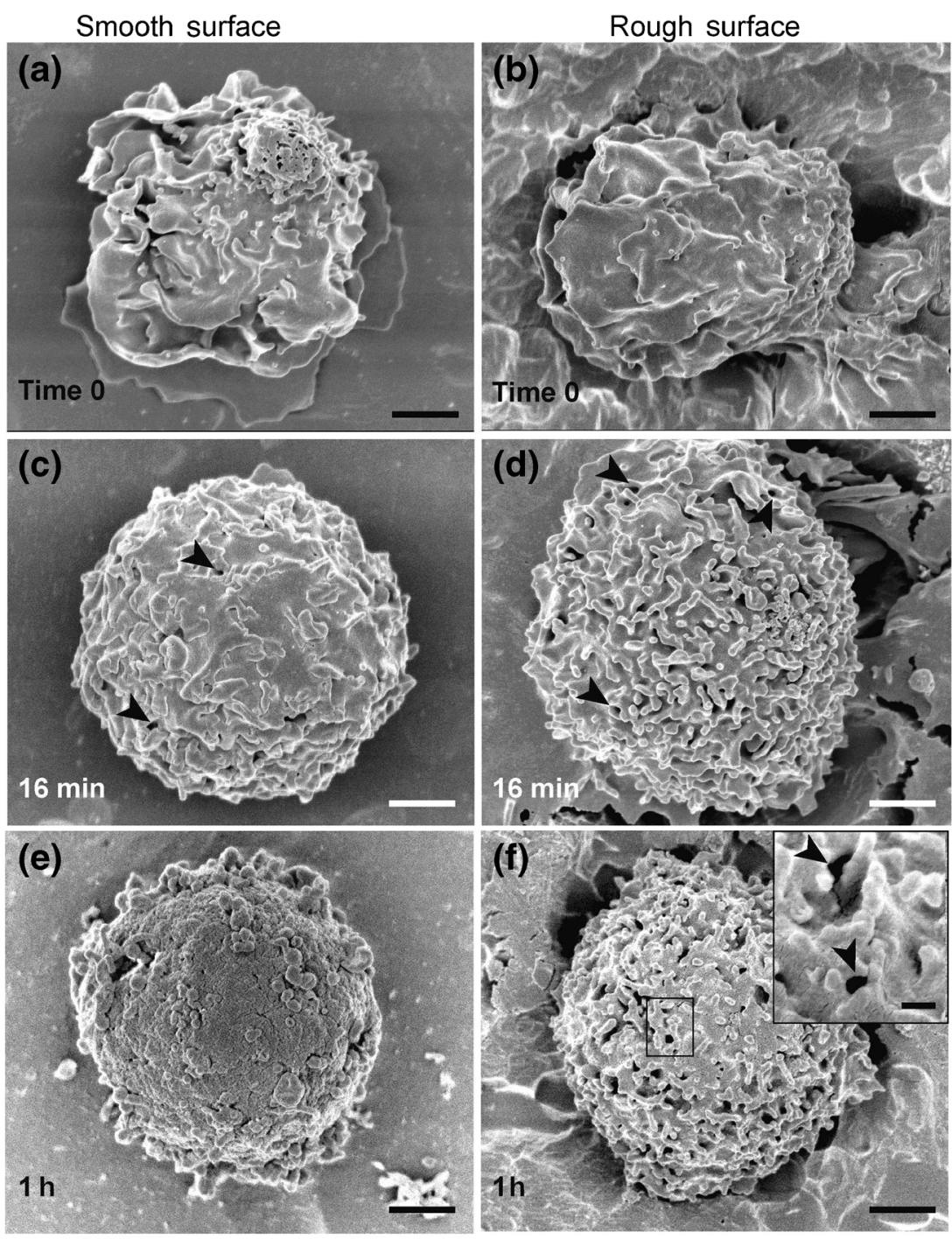

Figure 5. SEM micrographs of human PMNs adhering to smooth (a, c, e) or rough $(\mathbf{b}, \mathbf{d}, \mathbf{f})$ Ti surfaces after different times of contact. At $15 \min (\mathbf{c}, \mathbf{d})$ and $1 \mathrm{~h}(\mathbf{e}, \mathbf{f})$, PMNs on rough surfaces $(\mathbf{d}, \mathbf{f})$ show more surface villi and folds than cells on smooth surfaces (c, e). Note presence of small openings on cell surface (c, $\mathbf{d}, \mathbf{f}$, arrowheads). Number of these openings is higher on PMNs on rough surface (d) than on smooth surface (c), and is clearly increased after $1 \mathrm{~h}$ of contact with rough surface (f). Boxed area in (f) show cell surface openings at high magnification. Bar, $1 \mu \mathrm{m}$ (A-F); $200 \mathrm{~nm}$ (inset).

dramatically and new adhesion molecules have been identified (St Hill et al 2003). The physiological roles played by these molecules are being elucidated, which has led to the realization that certain subsets of adhesion molecules may be important in specific forms of inflammation. The complex relationships among adhesion molecules, cytokines and chemoattractants are also of active interest. However, less is known about the mechanisms of adhesion, spreading and activation of leukocytes in contact with Ti surfaces.
Because neutrophils are one of the first cells to reach the biomaterial surface during implant placement and are the most abundant participants in the immune response (Nygren et al 1997), we chose to study the morphology and adhesion characteristics of this cell type when in contact with smoothor rough-surfaced Ti surfaces.

Smooth Ti implants, which have been utilized experimentally and clinically since the first osseointegration procedures were performed, gradually have been substituted 

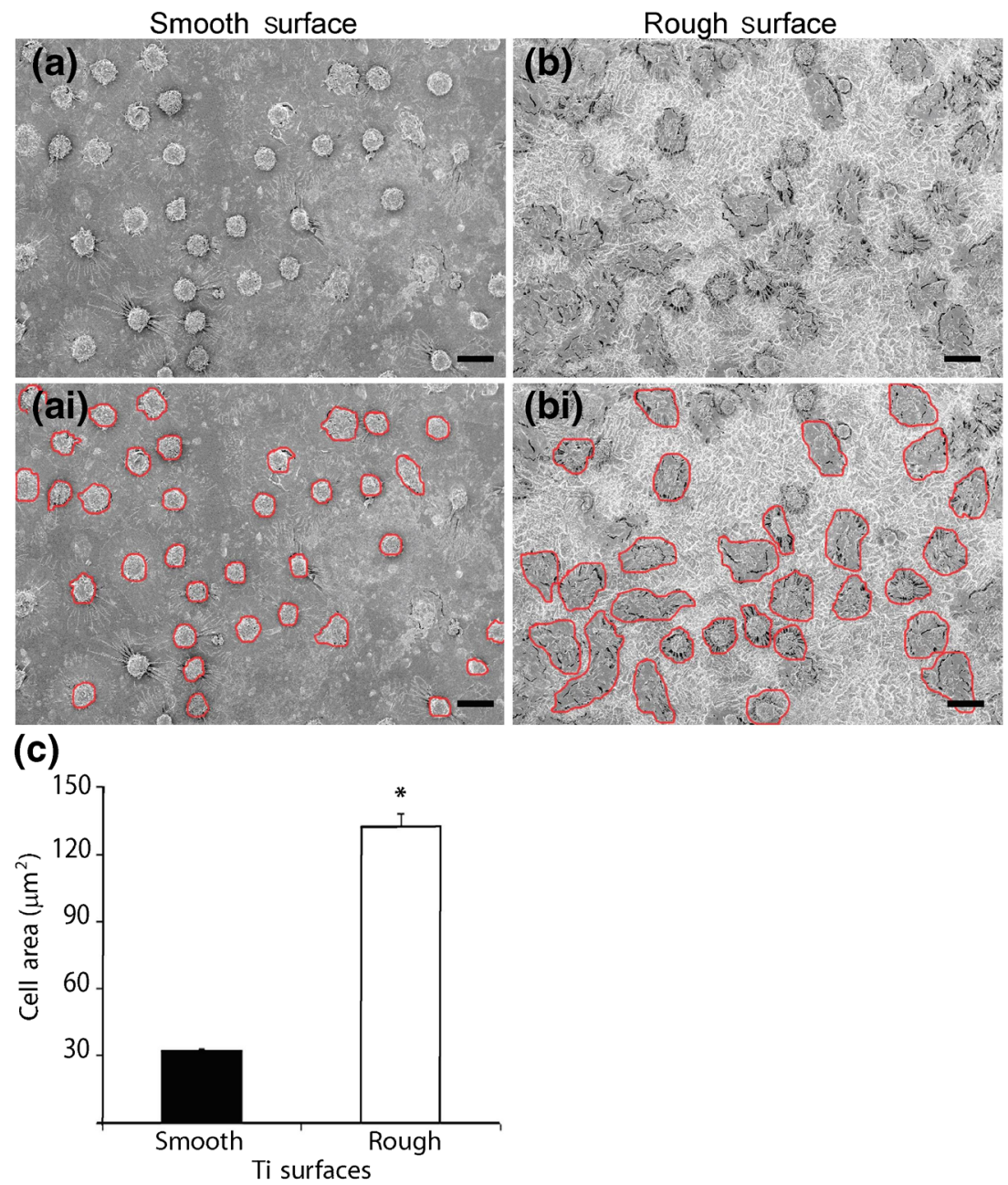

Figure 6. Human PMNs on rough surfaces show higher attachment areas than cells on smooth surfaces after $2 \mathrm{~h}$ of contact. Flat and round cells predominate on rough (b and bi) and smooth (a and ai) Ti surfaces, respectively. In $\mathrm{Ai}$ and $\mathrm{Bi}$, cells were delineated in red. (c) Cell surface attachment area (in $\mu \mathrm{m}^{2}$ ) was significantly higher in cells on rough surfaces than on smooth ones $(P<0 \cdot 01)$. A total of 112 cells were measured using Image J software and data were compared using Mann-Whitney U test (bar, $10 \mu \mathrm{m})$.

by rough-surfaced implants in the last 30 years. The influence of different characteristics on long-term implant survival has been demonstrated by many studies. In the present study, SLA treatment promoted an increased surface area compared to the smooth surface of the polished discs. As was shown by EDX analyses, SLA treatment was very efficient in removing contaminants such as alumina from the rough surfaces.

Much research has focused on the cell-implant interactions at the time-scale of weeks or months, whereas less is known about the earlier stages of cell contact (Borregaard et al 1994; Eriksson and Nygren 2001). Neutrophils could be removed easily from the implant surface immediately after contacting the Ti sheets. After $30 \mathrm{~min}$, cell detachment from the surfaces declined and the difference in adhesion between the surfaces was less evident. From 60 to $120 \mathrm{~min}$, the number of detached cells was quite similar between the surfaces.

Cell attachment and shape modifications help to regulate cell functions, such as protease secretion and proliferation (Lauffenburger and Horwitz 1996; Xiao et al 2004), that would be expected to influence implant performance. SEM results revealed different morphological features, such as folds, lamella, villi and openings, between the rough and 

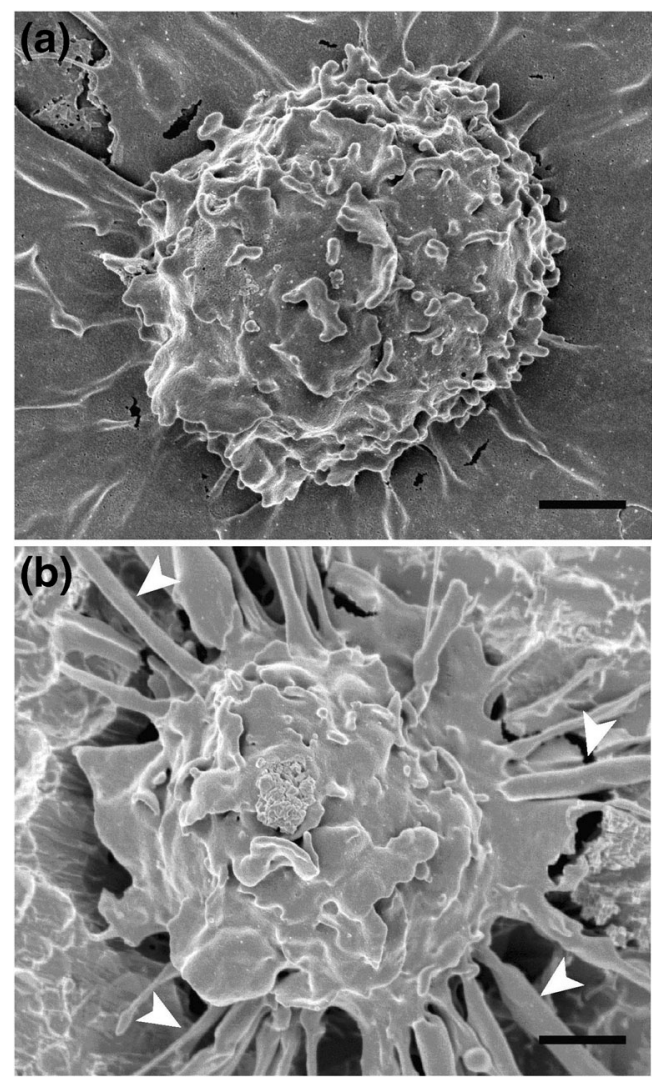

Figure 7. Cytoplasmic projections of human PMNs induced by Ti surfaces. Cells adhering to the rough surface (b) show a higher proportion of cytoplasmic projections (arrowheads) than cells in contact with the smooth surface (a) (bar, $1 \mu \mathrm{m}$ ). smooth surfaces. These findings indicate that cellular activation was dissimilar between the 2 surface types. Although the morphological differences coincided with different adhesion forces at an early stage, after $30 \mathrm{~min}$ of interaction with the Ti surface, the morphological differences became even more evident, while the adhesive properties became quite similar. Neither the early adhesion differences nor the morphological discrepancies between the cells exposed to the surfaces seemed to correlate with the CD62L or CD11b activation pathways. Although these membrane proteins showed an activation pattern, it did not correlate to the differences observed between the different surfaces. MAC-1 expression is correlated with lamellipodia formation on fMLP-activated cells (Mukherjee et al 1998), but we could not find studies identifying membrane proteins correlated to structural alterations triggered by surface contact with implants. Previous investigations have utilized other important membrane cell receptors, such as CD16, CD32, CD64, CD18, CD66b and CD162, but none of these studies compared smooth $v s$ rough surfaces or were performed in the absence of plasma. In this work, L-selectin and CD11b were chosen as the critical participants of the initial and late events of cell adhesion, respectively and the contact was tested directly against Ti plates, without the participation of plasma component or other cells.

\section{Conclusions}

The results demonstrated that PMNs adhere differentially to smooth or rough Ti surfaces and show morphological

Fluorescence intensity and percentage of cells presenting CD62L
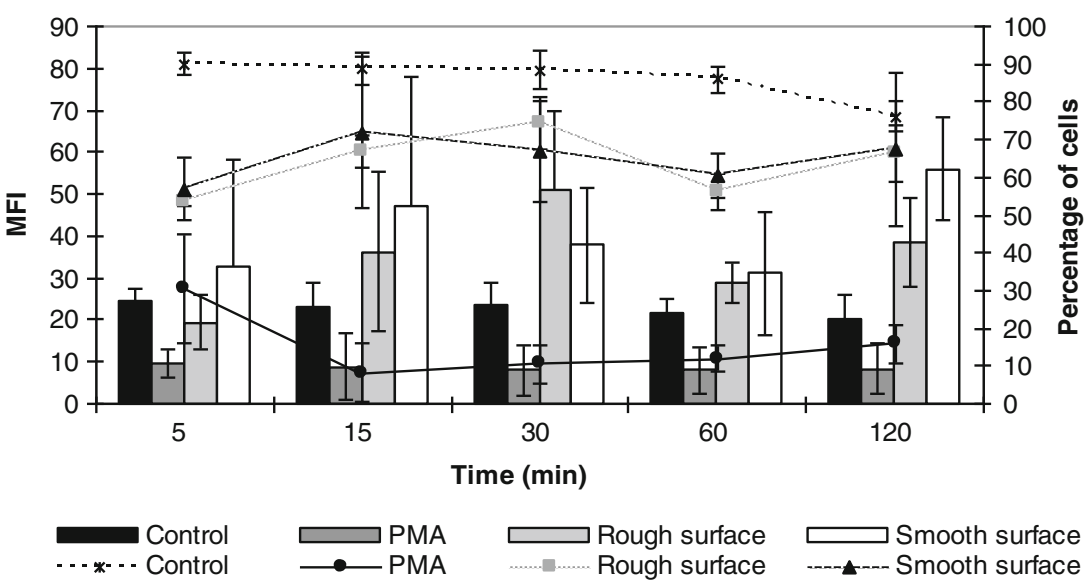

Figure 8. Percentage of cells presenting CD62L (lines) and MFI/cell (bars) after neutrophil activation with PMA or contact with smooth or rough Ti surface for 5-120 min. Anti-CD62L was used to detect expression of L-selectin on cell surface. Time had no effect on presence (F4.32 $=1.052 ; p=0.382)$ or amount of CD62L $(\mathrm{F} 4 \cdot 32=2 \cdot 037 ; p=0 \cdot 156)$. Significant differences in presence of CD62L (F3.8 = 96.246; $p=0.000$ ) were observed between control vs PMA, rough, or smooth surfaces and between PMA vs rough or smooth surfaces. Significant differences in MFI $(\mathrm{F} 3 \cdot 8=15 \cdot 813 ; p=0.001)$ were observed only between PMA $v s$ rough and smooth surfaces. 


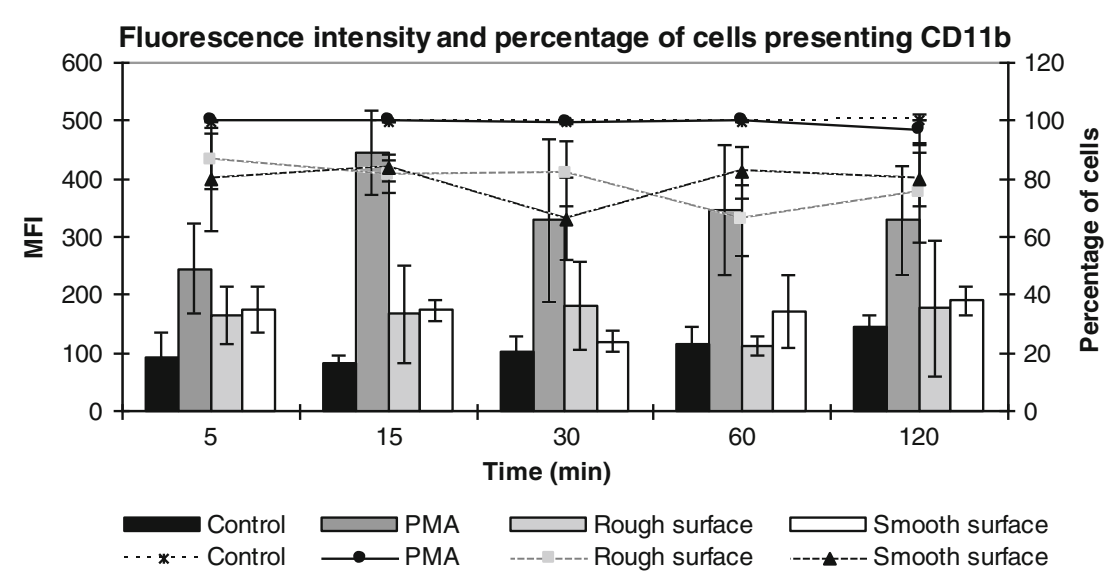

Figure 9. Percentage of cells presenting CD11b (lines) and MFI/cell (boxes) after neutrophil activation with PMA or contact with smooth or rough Ti surface for 5$120 \mathrm{~min}$. Anti-CD11b was used to detect expression of CD11b subunit. Time had no effect on presence of CD11b (F4.32 = 0.866; $p=0.459)$ or MFI (F4.32 = 1.376; $p=0.277)$. Significant differences in CD11b presentation $(\mathrm{F} 3.8=30 \cdot 803 ; p=0.000)$ were observed between control $v s$ rough or smooth surfaces and between PMA $v s$ rough or smooth surfaces. Significant differences in MFI (F3.8 $=15.813 ; p=0.001)$ were observed between PMA $v s$ control, rough surface, or smooth surface.

features that are typical for activated cells. The rough surface more effectively induced an initial adherence of cells compared to the smooth surface. Expressions of L-selectin and CD11b were influenced by the contact of the neutrophils with Ti, but not by differences in the surface textures. The adhesion processes occurred independently of the presence of other cells or plasma mediators. Further studies are necessary to determine the exact behaviour of the cells and the pathways by which these adhesion proteins are produced and expressed by neutrophils in direct contact with smooth and rough Ti surfaces. Physical contact seems to be enough to activate adhesive processes. Advances in material science have benefitted the development of surface engineering and nanotechnology. Understanding the cellular mechanisms regulating cell-implant interactions should help researchers to improve the surface topography of biomedical implant devices.

\section{References}

Albrektsson T B P, Hansson H A, Kasemo B, Larsson K and Lundstrom I et al 1983 Ann. Biomed. Eng. 111

Albrektsson T, Branemark P I, Hansson H A and Lindstrom J 1981 Acta Orthop. Scand. $\mathbf{5 2} 155$

Barbotin R G C C and Brown G 1976 Biomat. Med. Dev. Art. Org. 2205

Borregaard N, Kjeldsen L, Sengelov H, Diamond M S, Springer T A, Anderson H C, Kishimoto T K and Bainton D F $1994 \mathrm{~J}$. Leukoc. Biol. 5680

Bothe Rt B L and Davenport Ha 1940 Surg. Gynecol. Obstet. 71598

Castro M S, Cilli E M and Fontes W 2006a Curr. Protein Pept. Sci. 7473
Castro M S, De Sa N M, Gadelha R P, De Sousa M V, Ricart C A, Fontes B and Fontes W 2006b Protein Pept. Lett. 13481

Chehroudi B, Gould T R and Brunette D M 1992 J. Biomed. Mater. Res. 26493

Craddock P R, Fehr J, Dalmasso A P, Brighan K L and Jacob H S 1977 J. Clin. Invest. 59879

Ekdahl K, Nilsson B, Golander Cg, Elwing H, Lassen B and Nilsson Ur 1993 J. Colloid Interface Sci. 158121

Eriksson C and Nygren H 2001 J. Lab. Clin. Med. 13756

Erlandsen S L, Ottenwaelter C, Frethem C and Chen Y 2001 Biotechniques $\mathbf{3 1} 300$

Fontes B, Fontes W, Utiyama E M and Birolini D 1988 Dis. Colon. Rectum. 31298

Hong J, Nilsson Ekdahl K, Reynolds H, Larsson R and Nilsson B 1999 Biomaterials 20603

Ivetic A and Ridley A J 2004 Biochem. Soc. Trans. 321118

Kim H, Murakami H, Chehroudi B, Textor M and Brunette D M 2006 Int. J. Oral Maxillofac. Implants 21354

Kishimoto T K, Jutila M A, Berg E L and Butcher E C 1989 Science 2451238

Kumazawa R, Watari F, Takashi N, Tanimura Y, Uo M and Totsuka Y 2002 Biomaterials 233757

Lauffenburger D A and Horwitz A F 1996 Cell 84359

Leventhal G S 1951 J. Bone Joint Surg. Am. 33-A 473

Maciel N M, Schwartz C A, Rodrigues Pires Junior O, Sebben A, Castro M S, Sousa M V, Fontes W and Ferroni Schwartz E N 2003 Comp. Biochem. Physiol. B Biochem. Mol. Biol. 134641

Mcnally A K and Anderson J M 1994 Proc. Natl. Acad. Sci. USA 9110119

Morris C F, Castro M S and Fontes W 2008 Protein Pept. Lett. 15 995

Mukherjee G, Rasmusson B, Linner J G, Quinn M T, Parkos C A, Magnusson K E and Jesaitis A J 1998 Arch. Biochem. Biophys. 357164

Nusbacher J, Rosenfeld S I, Macpherson J L, Thiem P A and Leddy J P 1978 Blood $\mathbf{5 1} 359$ 
Nygren H, Eriksson C and Lausmaa J 1997 J. Lab. Clin. Med. 129 35

Ponce-Fatou J A 2006 J. Chem. Educ. 831147

Rainer T H 2002 Resuscitation 52127

Ridley A J, Schwartz M A, Burridge K, Firtel R A, Ginsberg M H, Borisy G, Parsons J T and Horwitz A R 2003 Science 302 1704

Rosengren A, Johansson B R, Thomsen P and Ericson L E 1994 Biomaterials 1517

Salzman E W, Lindon J, Mcmanama G and Ware J A 1987 Ann. NY Acad. Sci. 516184

Sevastianov V I 1988 Crit. Rev. Biocompat. 4109

Sperandio M, Smith M L, Forlow S B, Olson T S, Xia L, Mcever R P and Ley K 2003 J. Exp. Med. 1971355
St Hill C A, Alexander S R and Walcheck B 2003 J. Leukoc. Biol. 73464

Tang L and Eaton J W 1993 J. Exp. Med. 1782147

Tedder T F, Steeber D A, Chen A and Engel P 1995 FASEB J. 9866

Thomas K A and Cook S D 1985 J. Biomed. Mater. Res. 19875

Thomsen P, Larsson C, Ericson L E, Sennerby L, Lausmaa J and Kasemo B 1997 J. Mater. Sci. Mater. Med. 8653

Todd R F 3rd 1996 J. Clin. Invest. 981

Valois C R, Silva L P and Azevedo R B 2008 J. Endod. 34859

Vedder N B and Harlan J M 1988 J. Clin. Invest. 81676

Vroman L 1988 Bull. NY Acad. Med. 64352

Wagner J G and Roth R A 2000 Pharmacol. Rev. 52349

Xiao T, Takagi J, Coller B S, Wang J H and Springer T A 2004 Nature $\mathbf{4 3 2} 59$ 